ISSN: $1130-3743$

\title{
FAMILIA Y TRANSMISIÓN DE VALORES
}

\author{
Family and the values transmission
}

\section{Famille et transmission des valeurs}

\author{
Pedro OrTega Ruiz y Ramón Mínguez Vallejos \\ Universidad de Murcia. Facultad de Educación. Departamento de Teoria \\ e Historia de la Educación. Campus Universitario de Espinardo. Murcia. \\ Correo-e: portega@um.es-rminguez@um.es
}

Fecha de recepción: diciembre de 2003

Fecha de aceptación definitiva: marzo de 2004

BIBLID [(1130-3743) 15, 2003, 33-56]

RESUMEN

En este artículo se hace una breve exposición de la "situación" de la familia en el contexto de la sociedad occidental. La "crisis" de la familia y los diferentes modelos de la estructura familiar son abordados, desde una perspectiva sociológica, como marco real para una educación en valores en el ámbito de la familia. Se defiende el papel fundamental de la familia como estructura de acogida, de reconocimiento del recién nacido. En ella encuentran los hijos las "condiciones ambientales" imprescindibles para el aprendizaje de los valores: el clima moral, de seguridad y confianza, de diálogo y responsabilidad que haga posible, desde la experiencia, la apropiación del valor. No se contemplan otros enfoques de carácter cognitivo en la educación familiar. Se parte de la necesidad de hacer de la experiencia en el ámbito familiar la situación privilegiada e insustituible para el aprendizaje de los valores morales. La familia educa más por lo que "hace" que por lo que "dice".

Palabras clave: familia, protección, experiencia, aprendizaje, valores, diálogo, responsabilidad, seguridad. 
SUMMARY

This article makes a brief presentation of the family situation in the Western Society. The family crisis and several other family structure models are delt here from a sociological perspective, e. e., as a true framework for an education in terms of family. The family role is defended as a framework of protection in favour of the newborn. Therefore children can find an environment with "suitable conditions" that are of vital importance for learning of values that bear: morality, protection and assurance, dialogue and responsibility hence making the appropiation of values possible based on experience. No other focal points are contemplated that are cognitive in the family education except for the need to make the family environment a privileged and irreplaceable experience for the learning of moral values. The family brings up a child correctly for what it does rather than what it preaches.

Key words: family, protection, experience, values, learning, dialogue, responsibilty, assurance.

SOMMAIRE

Dans cet article on fait une brève exposition de la situation de la famille dans le contexte de la societé occidentale. La "crise" de la famille et les differents modèles de la structure familiale sont abordés d'un point de vue sociologique, comme cadre réel pour une education en valeurs au sein de la famille. On defend le rôle fondamental de la famille comme structure d'accueil, de reconnaissance de l'enfant que vient de naître. Au sein de la famille les enfants trouvent "les conditions d'atmosphère" indispensables pour l'apprentissage des valeurs: le climat moral, de securité et de confiance, de dialogue et de responsabilité qui rende possible a partir de l'experience, l'appropiation de la valeur. On n'envisage pas d'autres aspects de caractère cognitif dans l'éducation familiale. On part de la necessité de faire de l'experience dans le cadre familiale la situation privilegiée et irremplaçable pour l'apprentissage des valeurs morales. La famille enseigne plus parce ce qu'elle "fait" que ce qu'elle "dit".

Mots clef: famille, protection, experience, apprentissage, valeurs, dialogue, responsabilité, securité.

\section{1. ¿CRISIS EN LA FAMILIA?}

El término "crisis" es demasiado ambiguo como para describir una determinada situación de la familia. En una sociedad tan fuertemente sometida a cambios profundos y rápidos como la actual, que modifica constantemente sus formas de vida introduciendo nuevas concepciones económicas y nuevos desarrollos científicos y tecnológicos, no sólo la familia sino todo el conjunto de instituciones u organizaciones sociales se ven implicadas necesariamente en el cambio, si quieren 
sobrevivir en sus funciones. La adaptación a las nuevas necesidades que demanda la nueva realidad social es una exigencia que ninguna institución u organización social puede ignorar. No es posible pensar en una sociedad que se va transformando incesantemente que no encuentre mecanismos de adaptación como respuesta a las nuevas y muy diversas condiciones culturales, sociales y económicas en que ha de desenvolverse. No es que "la familia" esté en crisis, sino una determinada modalidad de familia (Pérez-Díaz y otros, 2000). Lo mismo puede afirmarse de otras instituciones u organizaciones sociales: sindicatos, partidos políticos, iglesia, etc.

La familia... cuenta con esa sinuosa característica de haber sido siempre percibida en situación de crisis, transición y dramática encrucijada. Siempre en constante perspectiva de cambio y dudoso futuro. Desde hace dos siglos, esta percepción dramática de la familia aparece con abrumadora reiteración, en la literatura apologética y, a veces, también en la científica (Iglesias de Ussel, 1998, 310).

Sí existe, sin embargo, una percepción social de crisis de la familia vinculada a la rapidez de los procesos de cambio en la institución familiar que siempre se han dado de un modo brusco, mediante "saltos", que mientras se asimilan, alientan imágenes de crisis e incertidumbre. La rapidez de los cambios en el escenario social, la dificultad para asimilar las transformaciones culturales y tecnológicas, la incorporación de los nuevos conocimientos, el impacto de la convivencia en la nueva cultura del mestizaje, etc., se han interpretado de un modo dramático y han favorecido, en gran manera, esta imagen de crisis de la familia que en la década de los sesenta y setenta alcanza un momento especialmente crítico. Es en estos años cuando la familia es vista por un determinado sector de la población española como una institución que había de ser expulsada de la vida ciudadana en tanto que sede de la violencia y la opresión cotidianas. Aún hoy, desde perspectivas ideológicas distintas, se siguen interpretando las diversas tendencias en la sociedad española hacia el descenso creciente de los matrimonios y el aumento de los divorcios, de los hogares unipersonales y de las familias monoparentales no tanto como signos del debilitamiento de una determinada modalidad de familia, sino como expresión de la crisis de la familia, en general, en tanto que institución vertebradora de la sociedad. Algunos subrayan, a este respecto, la pérdida de poder socializador de la familia y la mayor dependencia de la institución escolar. Se depende, cada vez más, de las escuelas para la educación de la infancia y de la juventud.

Resulta igualmente claro que la custodia de la infancia, antes asumida sin problemas por la gran parentela y la pequeña comunidad, ha pasado de no ser problema alguno a constituir el gran problema de muchas familias. Ciudades inabarcables y hostiles y hogares exiguos son ya parte del problema, al menos tanto como parte de la solución. En estas circunstancias, la sociedad se vuelve hacia lo que tiene más a mano, y en particular hacia esa institución más próxima a la medida de los niños, a menudo ajardinada y que cuenta con una plantilla profesionalizada en la educación: la escuela (Fernández Enguita, 2001, 64). 
La familia, se afirma, puede educar para la convivencia en los grupos primarios, pero es incapaz de hacerlo para la convivencia civil, puesto que no puede ofrecer un marco adecuado de experiencia. "Cuando la familia socializaba, la escuela podía ocuparse de enseñar. Ahora que la familia no cubre plenamente su papel socializador, la escuela no sólo no puede efectuar su tarea específica con la eficacia del pasado, sino que comienza a ser objeto de nuevas demandas para las cuales no está preparada" (Tedesco, 1995, 98). Algunos estudiosos de la familia muestran su preocupación por la transición de la vida familiar de lo que llaman la "Cultura del matrimonio" a la "cultura del divorcio", con las inevitables repercusiones que ésta conlleva en los procesos educativos de los hijos (Popenoe, 1993). Aunque la familia nuclear monogámica sigue siendo el modelo de familia predominante en la sociedad occidental (Eurostat, 2000), otras formas de convivencia empiezan a verse como formas o modelos alternativos de familia asumibles en una sociedad democrática, tanto política como socialmente. Ello, sin duda, introduce cambios importantes en los papeles que tradicionalmente venía desempeñando la familia en la socialización y educación de los hijos. Besharov (2003), en un estudio sobre la evolución de la familia americana, se muestra aún más pesimista: la familia está cerca de un cataclismo. La ausencia, casi completa, de normas de convivencia en el interior de la familia, la dificultad en el desempeño de roles estables, la ambigüedad o ausencia de valores que configuren patrones de comportamiento acaban desintegrando toda forma de vida familiar, al menos como, hasta ahora, la hemos entendido. En términos parecidos se pronuncia Fukuyama (1999) al establecer una estrecha asociación entre la tendencia de las familias hacia formas poco estables de convivencia con el aumento de comportamientos antisociales en niños, adolescentes y jóvenes.

No compartimos esta interpretación apocalíptica de la familia que nos parece excesiva e induce a error. "Creemos que ante lo que estamos, en las sociedades occidentales de hoy, es ante un nuevo avatar de esta institución milenaria, surgida del cruce de los usos de la antigüedad clásica, las tradiciones germánicas y el cristianismo, y cualificada sustancialmente por las transformaciones de todo orden de los cuatro últimos siglos" (Pérez-Díaz y otros, 2000, 11). Más que ante una muerte anunciada de la familia, estamos ante un desarrollo de formas o modelos plurales de familia, incluida la familia nuclear, como adaptación a las situaciones sociales cambiantes. Los recelos y, a veces, ataques contra la familia que a principios de los setenta eran frecuentes, en los últimos años, sin embargo, se constata una valoración positiva de la misma si bien desde formas nuevas de entenderla que, a nuestro juicio, no la desnaturalizan. Va tomando forma un nuevo movimiento que pretende volver a los "valores familiares" (Beck-Gernsheim, 2003). En efecto, en la última década distintos colectivos profesionales como pedagogos, psicólogos, abogados, asistentes sociales, etc., están intensificando su interés por la realidad familiar, sin que esto haya de interpretarse como una vuelta a formas y normas de otros tiempos. Desde análisis que responden al conocimiento de la nueva realidad social, 
la familia se ha convertido hoy en objeto de atención preferente para las instituciones públicas y privadas.

Quienes hace más de dos décadas... se atrevieron a profetizar la muerte de la familia, poseen ya motivos más que suficientes, ante la evidencia histórica, para empezar a rectificar su pronóstico. La familia sigue existiendo, y sigue prestando un servicio insustituible al desarrollo y apoyo personal. Más que un obstáculo para el desarrollo individual, la familia sigue siendo una realidad y un proyecto en el que se continúa creyendo, en el que se invierten la mayor parte de las energías personales, y del que se espera que sea la fuente principal de nuestra satisfacción individual (Gimeno, 1999, 21).

Los temas de estudio sobre la familia en la última década no han supuesto un cambio sustantivo respecto de los estudios realizados en décadas anteriores (González Anleo, 2001). Aspectos demográficos, cambios en la estructura y dinámica familiar, conflictos y rupturas, atención a la familia por parte de las instituciones públicas, etc., han centrado el interés de los estudiosos sobre la familia. Sin embargo, se constata en estos trabajos una escasa atención por la socialización de los hijos y la educación de éstos en el recinto privado de la institución familiar. Este olvido del papel fundamental que desempeña la familia en la educación de los hijos contrasta con la importancia que los españoles atribuyen a la misma situándola a la cabeza de sus preferencias valorativas (99\%), por encima del puesto de trabajo, religión y política (Orizo y otros, 2000). El exagerado moralismo de antaño, implantado desde una concepción homogénea de la sociedad y de una autoridad doctrinal indiscutible, el carácter estático y patriarcal, capaz de sacrificar la singularidad individual en aras del mantenimiento de una estructura heredada, explica el silencio y el destierro de la familia en el debate sobre la construcción de la nueva sociedad en épocas pasadas. Habría que fundamentar (era el nuevo discurso de la década de los sesenta y setenta) la convivencia u orden social sobre nuevos valores, sobre instituciones y organizaciones que favoreciesen el cambio social. Y en esta tarea de reconstrucción social la familia, se entendía, no estaba a favor del cambio, sino de la continuidad.

El cambio profundo producido en la sociedad postindustrial sociológicamente laica, incorporada a los avances tecnológicos de la información, ha llevado consigo el debilitamiento de la institución familiar como ámbito autosuficiente y mecanismo básico de transmisión de valores; pero también ha supuesto la recuperación de un nuevo discurso sobre la familia, alejado de todo fundamentalismo excluyente, ha puesto de manifiesto su extraordinaria capacidad de adaptación a un contexto tan cambiante como el actual, ha permitido la superación de prejuicios y facilitado el estudio riguroso de la dinámica familiar desde las aportaciones de las ciencias más diversas. En resumen, ha favorecido la vuelta a la consideración del papel fundamental de la familia en el proceso de construcción de la personalidad de los hijos y de integración de las jóvenes generaciones en la sociedad. Nadie puede hoy razonablemente dudar de que la educación familiar tiene una repercusión decisiva en la manera como los hijos se comportan y se desenvuelven posteriormente en la 
sociedad. Ha muerto un modelo familiar que anulaba la iniciativa individual, pero en su lugar empieza a surgir otro u otros modelos familiares cuyos valores se impregnan de un modelo social más igualitario y personalizado, más democrático y más abierto al futuro que al pasado (Gimeno, 1999). Surgen nuevas formas de entender la familia, nuevas formas de convivencia basadas más en las interacciones personales, en las que cada miembro de la familia pueda sentirse realizado dentro de un proceso complejo de construcción personal (Castell, 1998).

Algunos autores se preguntan sobre la existencia misma de la familia. A los ojos de cualquier observador aparecen grupos de personas que viven comunitariamente en su propio hogar. Pero no resulta fácil definir el concepto sociológico de familia dado el polimorfismo de las manifestaciones, la gran variedad de agrupamientos sociales que, según los diferentes pueblos y culturas, podrían llamarse "familia" (Pastor, 2002). Algunos incluso afirman que no es posible dar una definición de familia porque ésta es sólo una construcción ideológica, histórica y política, una mera categoría mental. Otros piensan que es sólo una abstracción mental que reúne una gran variedad de formas, pero que ese concepto no se plasma como tal en la realidad. Aunque las formas de la familia sean muy diversas no puede dudarse de que ésta sea una realidad empírica cuya génesis aparece como un lento proceso de institucionalización por el que ciertas prácticas, usos o costumbres culturales adoptadas a lo largo del tiempo por un pueblo cristalizan poco a poco en estructuras grupales que luego permanecen. Pero no sólo el hecho de compartir la vivienda define a la familia. También el sentimiento de parentesco es un indicador fundamental de la misma. Desde un punto de vista sociológico podría definirse la familia como "aquellos pequeños grupos primarios residenciales cuyas relaciones internas están socialmente institucionalizadas según normas de parentescon (Pastor, 2002 , 23). Con ello se alude no sólo a los vínculos genealógicos, sino también a las relaciones socialmente institucionalizadas entre unas determinadas personas que se sienten mutuamente pertenecientes. No es nuestro propósito discutir aquí sobre el concepto o definición de ufamilia". Ello nos llevaría a un debate en el que los elementos ideológicos, políticos, morales y religiosos necesariamente tendrían cabida. Compartimos la idea de que no existe una única definición, o que la diversidad de la vida familiar no puede reducirse a una única definición (Gracia y Musitu, 2000). El término "familia" se nos muestra como una compleja unidad significante, tan pronto como la pronunciamos nos vemos envueltos en la maraña de un problema lingüístico. Una maraña de significados e interpretaciones tan compleja que nos disuade de cualquier pretensión de encontrar posibles convergencias o afinidades en su definición ante tanta multiplicidad y diversidad. "El concepto de familia es complejo y difícil de delimitar y lo es más si añadimos ahora la multiplicidad de formas y funciones familiares que varían en función de las épocas históricas, de unas culturas a otras, e incluso en grupos y colectivos dentro de una misma culturan (Gracia y Musitu, 2000, 43). Nos limitamos, por tanto, a la sola consideración sociológica de la familia tal como ésta aparece en sus distintas manifestaciones en la sociedad occidental, por lo que habría que entender la "familia" en un sentido 
amplio no restringido, sin que su concepto pueda considerarse vinculado a una determinada opción política, moral o religiosa. Nuestra pretensión en este trabajo es construir un discurso pedagógico, no hacer sociología. Sin embargo, sí consideramos pertinente consignar algunos de los cambios más relevantes que la familia en España ha experimentado en las últimas décadas, y que la distinguen de la familia del inmediato pasado: 1) El reconocimiento legal de la libertad de los adultos para vincularse o desvincularse para formar una pareja o para deshacerla; 2) en las relaciones de pareja se concede mucho valor al grado de pasión, amor, intimidad y bienestar en la convivencia; 3) los roles de género tradicionales han entrado en crisis. El padre no es la autoridad indiscutible y la mujer no permanece necesariamente en el hogar. Las actividades domésticas y la crianza de los hijos tienden a compartirse; 4) los valores de la independencia, libertad, derecho al bienestar individual y promoción personal son factores que han incidido en la fecundidad y en la organización y funcionamiento de la familia. Estos cambios experimentados en la familia actual la alejan de otras formas o modelos dados en el pasado (Thiebaut, 1998). Los cambios producidos han significado el paso de la familia como institución a la familia fundada en la interacción personal.

Hay un rasgo, escribe Iglesias de Ussel $(1998,44)$, que puede sintetizar muchos de los cambios y, sobre todo, de las imágenes sociales de la familia en la sociedad española: Se ha pasado de una configuración monolítica de la familia a otra pluralista en la que las distintas modalidades de articular la vida familiar... reciben semejante cobertura legal.

\section{FAMILIA Y EDUCACión EN VALORES}

Hace sólo unas décadas se confiaba, ingenuamente, en el poder configurador del sistema educativo formal capaz de ofrecer experiencias suficientemente ricas para hacer posible en los educandos la apropiación de valores y el desarrollo de una personalidad integrada. Todavía hoy se sigue confiando en que la escuela resuelva los problemas que la sociedad actual está generando. Drogas, violencia, consumismo, contaminación ambiental, etc., constituyen nuevas exigencias o contenidos curriculares que deben incorporarse a los programas escolares en el convencimiento de que la institución escolar es el marco idóneo, cuando no suficiente, para abordar estos problemas. Tal pretensión empieza a ser desmentida por los hechos. Las actitudes y creencias que apoyan las conductas dependen más del clima social y familiar que de la actuación del medio escolar. Éste actúa como refuerzo o elemento corrector de las influencias permanentes que el niño recibe en el medio sociofamiliar, pero en ningún caso lo sustituye adecuadamente. Ambas instituciones se entienden como necesariamente complementarias e indispensables en el proceso de adaptación social y construcción de la personalidad del niño. Ni siquiera en los llamados aprendizajes cognitivos, que podrían entenderse como de exclusiva 
competencia de la escuela, ésta es autosuficiente. Hoy ya nadie duda que el mundo de los saberes o conocimientos que los alumnos deben adquirir en la sociedad de la información desborda ampliamente los límites estrechos del recinto escolar. No es tanto la información que la escuela transmite lo que ahora se valora, sino su función facilitadora y orientadora en la búsqueda de información y en el uso que se hace de la misma.

...la escuela basada únicamente en la transmisión de la información ha perdido toda su razón de ser. Hay más información de la que podemos soportar. Ya no hay un lugar y una edad para el aprendizaje. Entramos en la sociedad del aprendizaje y en la vida del aprendizaje (Rodríguez Neira, 2000, 17).

$\mathrm{Si}$ atendemos a los valores como patrones de conducta, no se puede olvidar que los niños que van a nuestras escuelas vienen ya equipados con unos determinados valores (y antivalores) a través de los cuales filtran las inevitables propuestas valorativas que la escuela a diario realiza. Ninguna de ellas dejará de estar interpretada por el modo de pensar y vivir de la propia familia (Beltrán, 2001). Las actitudes y creencias, los valores y antivalores están en la base de aquello que el niño piensa y hace. $Y$ los valores y antivalores del niño conectan directamente con el medio sociofamiliar. "(de la familia) depende la fijación de las aspiraciones, valores y motivaciones de los individuos y en que, por otra parte, resulta responsable en gran medida de su estabilidad emocional, tanto en la infancia como en la vida adulta" (Flaquer, 1998, 36). Esto obliga a pensar en la institución escolar de "Otra manera", a modificar su estructura tradicional y a revisar en profundidad las propuestas escolares en el ámbito de los valores. Constituye un error seguir haciendo propuestas educativas para la resolución de los conflictos (violencia) en la escuela marginando a la familia (Ortega, 1997; Cerezo, 2001), cuando el conflicto en las aulas tiene un origen sociofamiliar (Ortega, Minguez y Saura, 2003). El tratamiento que los especialistas (pedagogos y psicólogos) están dando al tema tan actual de los conflictos y la violencia en la escuela pone de manifiesto la insuficiencia de la institución escolar para la integración de determinados alumnos en la vida de la escuela. Todos vienen a incidir en la ineludible participación de la familia en cualquier programa de intervención, si se quiere abordar con algunas garantías de éxito dicho problema, aunque no siempre las propuestas sean coherentes con los propósitos enunciados.

Si tenemos en cuenta que la parte del entorno que es más significativa para el niño durante los primeros años de vida es la familia, y especialmente los padres, podemos pensar que las conductas agresivas se generan en el ambiente familiar; es más, que los padres enseñan a sus hijos a ser agresivos quizás de manera no premeditada (Cerezo, 1999, 57).

Lo que ya nadie duda es que los modelos de conducta que ofrecen los padres, los refuerzos que proporcionan a la conducta de sus hijos facilitan el aprendizaje de conductas violentas o respetuosas con los demás. 
La carencia de estructuras que sirvan de marco de referencia para el niño; las prácticas de disciplina inconsistentes; el refuerzo positivo a la respuesta violenta; el empleo de castigos físicos y psíquicos; la carencia de control por parte de los padres y la historia familiar de conductas antisociales explican suficientemente el comportamiento antisocial, a veces violento, de los niños en el centro escolar" (Ortega, Mínguez y Saura, 2003, 41).

Son abundantes los estudios sobre la influencia de la familia en la construcción de la personalidad del niño y de su comportamiento (Krevans y Gibbs, 1996; Eisenberg, Fabes y Murphy, 1996; Kochanska, 1997). La seguridad afectiva, indispensable para la formación de una personalidad sana, está estrechamente vinculada al apoyo emocional sensible recibido del entorno familiar (Berkowitz, 1996; Flaquer, 1998). Estudios recientes (Castro, Adonis y Rodríguez, 2001) vinculan la actitud violenta de los hijos con la ausencia de las figuras paterna y materna y la educación familiar. Y avanzan resultados: 1) Hay cierta evidencia acerca de la vinculación entre el estilo laissez faire con el hecho de que los padres trabajen; 2) el estilo laissez faire es el que más interés produce en los adolescentes por manifestarse como violentos y agresivos; 3) la influencia de los estilos educativos repercute de manera diferente en el interés de los/as adolescentes por manifestarse como violentos y agresivos; 4) la influencia de las figuras paterna y materna es desigual, siendo más decisiva la influencia materna. Barudy (1998) describe las consecuencias en el comportamiento de los niños que sufren graves carencias en el trato con sus padres, o son abandonados por éstos: trastornos del apego, aislamiento social, autoestima baja, dependencia y desconfianza social, comportamientos agresivos, tristeza y ansiedad crónicas, depresión, etc. A la abundancia de estudios en el ámbito de la psicología, sociología y el derecho sobre la realidad familiar, producida en las últimas décadas, no le ha acompañado análoga preocupación en el ámbito de la pedagogía. Para ésta, la educación familiar sigue siendo todavía, en nuestro país, un ámbito insuficientemente tratado, aun reconociendo la influencia de la familia en el proceso de socialización del niño, en el aprendizaje de actitudes, valores y patrones de conducta. No hemos logrado aún despojarnos de viejos estigmas que durante décadas han acompañado a la educación familiar. Ésta sigue disfrutando, entre nosotros, de un estatus menor, aunque reconozcamos, basados en el conocimiento de la propia experiencia, que

la organización familiar deja una huella impresa que acompañará a los seres humanos durante toda su vida. Las primeras experiencias son como surcos que se abren en la mente de quien las recibe. Después aparecen otras. Y la vida se hará compleja, armónica o disarmónica, integrada o desorganizada, placentera o traumática, pero en el fondo, a veces oculto, a veces patente, quedarán las vivencias iniciales como patrimonio de la propia personalidad (Rodríguez Neira, 2003, 21).

La familia es el hábitat natural para la apropiación de los valores. Hacer esta afirmación tan rotunda puede parecer que atribuimos un poder taumatúrgico a la institución familiar, un carácter casi sagrado. No es ésa nuestra intención. Aunque 
atribuyamos a la familia una función acogedora en tanto que centro de alivio de tensiones, ofreciendo a todos sus miembros un clima sereno, hecho de sosiego, tranquilidad y seguridad que sirve de contrapunto a las tensiones propias de la vida y de la sociedad moderna en que vive (Beltrán y Pérez, 2000), reconocemos, también, que la familia no es la única agencia educativa, y menos aún socializadora en la sociedad actual, ni creemos que sea correcto establecer separación o contraposición alguna entre familia y sociedad. La familia refleja las contradicciones sociales de la sociedad actual, y como ésta aparece inmersa en un mar de cambios profundos que afectan de un modo desigual a los padres y a los hijos. Depende de la sociedad tanto en su configuración como en sus propósitos. No cabe duda de que el avance experimentado en la sociedad occidental en la defensa y ejercicio de las libertades, la tutela jurídica sobre las minorías étnicas y culturales, la extensión de la educación a toda la población, la implantación progresiva de una cultura de la tolerancia y la mayor conciencia del deber ciudadano de participar en los asuntos públicos constituyen muestras y marcos para una educación social del ciudadano de hoy. Actualmente se está produciendo un vigoroso y prometedor discurso sobre la urban education que rompe los moldes de una educación encerrada en los muros de los centros escolares. Pero junto a estas realidades es evidente, también, que los medios de comunicación ejercen un poder casi omnímodo en la configuración de los modos de pensar y vivir, dejando poco espacio libre que escape a su control. Un examen atento a la realidad social de nuestro tiempo nos puede llevar a pensar que asistimos a una gran representación teatral en la que los auténticos actores no están en el escenario, sino detrás del telón, en la trastienda. Las grandes decisiones políticas, económicas y sociales no se toman por y para los directamente afectados. Otros les "ahorran" el trabajo y el riesgo de pensar y equivocarse. Por otra parte, se detecta la presencia cada vez más activa de los nuevos movimientos sociales que están haciendo posible una mayor atención a los aspectos culturales y a la calidad de vida de los ciudadanos; están facilitando la conquista de mayores oportunidades para participar en las decisiones que afectan a la vida de cada uno, dando un mayor protagonismo a los grupos sociales de autoayuda y a formas cooperativas de organización social, denuncian la instrumentación del poder y exigen un reparto equitativo de los bienes (Dalton y otros, 1992). No es, por tanto, la familia la única agencia educativa, aunque sí sea la más importante como fuente de identificación emocional. "A medida que se ve privada de entidad como institución, más la valoramos. Uno de los principios que rigen la ciencia económica es que lo que valoramos es justamente la escasez y no la abundancia. En el plano de los afectos sucede exactamente lo mismo. Si en los años sesenta la familia sobraba, ahora falta" (Flaquer, 1998, 199). Y es, además, la más influyente en el aprendizaje de valores, de patrones valiosos de conducta y, también, su marco más adecuado. Cuando éste fracasa o no se da, resulta muy difícil la suplencia.

La abundante bibliografía producida a raíz de la LOGSE ha incidido en el papel de la escuela en la enseñanza de los valores como marco adecuado (¿y suficiente?) y ha puesto aún más de relieve la profunda disociación existente entre la familia y 
la escuela. Es difícil encontrar alguna referencia a su carácter complementario y limitado que demanda y exige la vinculación a una experiencia del valor en el ámbito de la familia. Es decir, el valor se aprende si éste está unido a la experiencia del mismo, o más exactamente, si es experiencia. No se puede aprender el valor de la tolerancia y la solidaridad si no se tienen experiencias de esos valores, es decir, de modelos de conducta tolerante. No se aprende el valor porque se tenga una idea precisa del mismo. No es la claridad cartesiana de los conceptos la razón suficiente que mueve y hace posible el aprendizaje de los valores, sino el hecho de su traducción en la experiencia. Y sólo cuando el valor es puesto en práctica por el propio educando, cuando tiene experiencia de su realización personal, puede decirse que se da un aprendizaje o apropiación del valor (Ortega y Mínguez, 2001). No enseñamos los valores porque hablemos de ellos, sino porque ofrezcamos experiencias de los mismos.

Los humanos nacemos con abundantes carencias y con casi todo por aprender. Actitudes, valores y hábitos de comportamiento constituyen el aprendizaje imprescindible para "ejercern de humanos. Nadie nace educado, preparado para vivir en una sociedad de humanos. Pero el aprendizaje del valor es de naturaleza distinta al de los conocimientos y saberes. Exige la referencia inmediata a un modelo. Es decir, la experiencia suficientemente estructurada, coherente y continuada que permita la "exposición" de un modelo de conducta no contradictoria o fragmentada. Y esto es difícil encontrarlo fuera de la familia. Es verdad que no existen experiencias, tampoco en la familia, que no presenten, junto a aspectos positivos, otros claramente rechazables. Pero, a pesar de los contravalores o experiencias negativas, en la familia se puede identificar la línea básica, la trayectoria vital que permite valorar y reconocer en ellas la existencia y estilo personal de la vida de un individuo. Junto a conductas no deseables, la estructura familiar ofrece la posibilidad de contrastarlas con otras valiosas, valorarlas, dar explicaciones de ellas. Y permite, sobre todo, una experiencia continuada del valor. La enseñanza del valor no se identifica con el aprendizaje de conceptos o ideas. Se hace a través de la experiencia, y ésta debe ser continuada en el tiempo. Quiere ello decir que una experiencia aislada, puntual no da lugar, ni es soporte suficiente para un cambio cognitivo, ni para la adhesión afectiva y compromiso con el valor. Es el conjunto de las experiencias valiosas las que van moldeando el pensamiento y el sentimiento del educando, encontrando en las relaciones afectivas con el modelo la comprensión del valor y el apoyo necesario para su adhesión. Y en esto, el medio familiar ofrece más posibilidades que el marco más heterogéneo de la escuela y, por supuesto, de la misma sociedad donde conviven o coexisten distintos sistemas de valoración y experiencias muy distintas de valores y antivalores.

La escuela es una institución más que interviene en la esfera de la educación moral. Y mientras que en el ámbito del saber existe una amplia tradición y una lógica disciplinar que otorga coherencia a la acción educativa, en la esfera de la formación moral hay un bagaje mucho más reducido y una menor influencia en comparación con otros entornos sociales (Marchesi, 2000, 178). 
En el aprendizaje del valor se hace necesario algo más: el clima de afecto, de aceptación y comprensión que envuelven las relaciones de educador y educando. La apropiación del valor no es fruto de una simple operación de cálculo, interviene, en gran medida, la mediación del modelo que hace atractivo, sugerente un valor. Éste aparece estrechamente vinculado a la experiencia del modelo, y su aprendizaje depende tanto de la "bondad" de la experiencia cuanto de la aceptaciónrechazo que produce en el educando la persona misma del modelo (Ortega y Mínguez, 2001). Si en el aprendizaje de conocimientos, el establecimiento de un clima positivo en las relaciones profesor-alumno se muestra claramente influyente, en el aprendizaje de los valores se hace indispensable. Éstos se aprenden, diríamos, por ósmosis, por impregnación. Y no basta con acudir a la experiencia de otros modelos ajenos a la familia o a la escuela. El educando (niño-adolescente) tiende a identificar la experiencia de un valor con el modelo más cercano: padres, profesores y personas significativas de su entorno. Queremos decir que la propuesta de un valor, para ser eficaz, debe hacerse en un contexto de relación positiva, de aceptación mutua, de afecto y "complicidad" entre educador y educando, porque el valor que se propone, desde la experiencia del modelo, forma parte de la trayectoria y estilo de vida de éste. El niño-adolescente no aprende una conducta valiosa independientemente de la persona que la realiza. Se sentirá más atraído por ésta si la ve asociada a una persona a la que, de alguna manera, se siente afectivamente ligado. En la apropiación del valor hay siempre un componente de pasión, de amor. Por ello, el inicio de la educación en valores debe producirse en el entorno sociofamiliar en que vive el niño. Llevar esto a cabo implica rescatar el carácter vulgar, cotidiano del valor y hacer del medio familiar el marco habitual, "natural", no único, de la enseñanza del valor, asumiendo el riesgo de acercarse a una realidad contradictoria en la que conviven valores y antivalores como es el ámbito familiar. Pero con ello estaremos siempre ante modelos de carne y hueso, al alcance de todos, es decir, imitables.

\section{La PEDAGOGÍA DE LOS VALORES EN EL ÁMBITO FAMILIAR}

Antes se ha dicho que la enseñanza de los valores está asociada a la experiencia de los mismos. Se trata, por tanto, de ofrecer a los hijos ambientes o climas en los que puedan tener habitualmente experiencias del valor; y que sea la realidad cotidiana de la vida familiar la que se convierta en referente principal, no exclusivo, de los valores para los hijos. Sería atrevido, por nuestra parte, hacer aquí un elenco de aquellos valores que hoy deberían proponer los padres a sus hijos. Además de atrevido, no sería tampoco pertinente. Cada familia escoge para sí y sus hijos los valores que considera más coherentes o prioritarios con una determinada concepción del hombre y del mundo. Y en una sociedad tan compleja y plural como la nuestra los sistemas de valores son también muy diversos. Nos limitamos, por tanto, a exponer las que consideramos "condiciones ambientales" para la enseñanza y aprendizaje de los valores en el ámbito familiar. 
La familia no es un sistema autárquico, impermeable a las influencias del entorno. Los cambios sociales, políticos, económicos e ideológicos han modificado profundamente el estilo educativo de la familia en nuestro país. Nada es igual en las prácticas y orientaciones educativas de hoy tras la aprobación de la Constitución de 1978. Un régimen democrático de libertades ha transformado la vida de los individuos, los grupos e instituciones, penetrando en todas las áreas y manifestaciones de la vida social y originando una nueva forma de entender la persona y la vida. A estos cambios no ha escapado, obviamente, la familia. Debe aprender a ejercer nuevos papeles, nuevas funciones o, al menos, a ejercer de forma distinta las que ya venía realizando. Ello exige, en primer lugar, vencer la resistencia al cambio, la fijación a un pasado que ya no sirve como modelo válido para una realidad del todo distinta. Y, en segundo lugar, preparar a los padres para ejercer nuevas competencias que consideramos son la "puerta de entrada" al aprendizaje de los valores en el ámbito de la familia. En concreto, dentro de las "condiciones ambientales" para la enseñanza y aprendizaje de los valores destacamos la función de acogida y el clima moral y de diálogo.

\subsection{La función de acogida}

La sociedad tecno-científica ha propiciado la creación de una imagen de la persona eficaz, competitiva que ha penetrado profundamente en las estructuras sociales y ha configurado todo un estilo de vida. Se constata un debilitamiento de las tradiciones comunes que en tiempos pasados ofrecían valores compartidos de referencia en los que todos, de alguna manera, podían participar. El problema de fondo es que al desaparecer esas creencias universales compartidas resulta muy difícil encontrar una nueva base general de orientación que constituya el punto de encuentro en la construcción de la sociedad. No sólo a nivel social, también el individuo concreto ha quedado huérfano de modelos próximos de socialización. Si algo caracteriza al momento actual es la pérdida de capacidad de las instituciones tradicionales para la transmisión de valores y pautas de comportamientos deseables, empujadas cada vez más al recinto de lo privado y a competir con otras agencias en la propuesta de modelos de vida. La crisis, se admite, afecta a todas las estructuras de acogida (familia, comunidad, sociedad) e incide en todas las relaciones fundamentales que los habitantes de nuestro espacio cultural mantienen con la naturaleza y entre sí (Duch, 1997). Asistimos a una indudable crisis de vínculos, de ataduras, es decir, de lazos culturales profundos, de sentimientos de filiación social; vacío que genera un sentimiento de anomía enfermiza cuya expresión más inmediata es el incontenible deseo de recrear un sentimiento de pertenencia grupal (Dahrendorf, 1993). Resulta bastante evidente que nos encontramos metidos de lleno en "tierra de nadie": los antiguos criterios han perdido su originaria capacidad orientativa, y los nuevos aún no se han acreditado con fuerza suficiente para proporcionar a los individuos y grupos sociales orientación y colocación en el entramado 
social. En este contexto, la familia desempeña, todavía, una función esencial: ser una institución o estructura de acogida.

Cuando nace, el hombre es un ser completamente desorientado, sin puntos de referencia fiables... Su paso por los caminos del mundo dependerá de manera importantísima de la acogida que experimente, de la orientación que se le proporcione, de la competencia gramatical que llegue a adquirir por mediación de los procesos pedagógicos en los que deberá integrarse (Duch, 1997, 15-16).

La familia, como estructura de acogida, ha sido determinante para el desarrollo del ser humano en todas las etapas que ha recorrido la historia de la humanidad. Desde una perspectiva sociológica, la familia facilita la integración de los individuos en el sistema social. Es el vehículo privilegiado a través del cual el individuo se convierte en miembro de una sociedad. Sus actitudes, valores, patrones de conducta, aspiraciones, cómo percibe a los demás y a sí mismo, van a estar condicionados por la familia. De ahí que la familia constituya el contexto o nicho más apropiado, en cuyo interior, cada nuevo individuo comienza a construir su identidad personal, el modo concreto de ser humano y vivir en sociedad. Ello exige un clima de afecto e interés por todo lo que rodea al niño, no sólo por su persona; y explica, además, que sea el intercambio de afecto y de apoyo, de confianza y comunicación, de cariño y respeto mutuos, en definitiva, el ambiente o clima emocional que se construye en el ámbito de la familia los objetivos básicos en la vida de las familias españolas (Pérez-Díaz y otros, 2000). Es cierto que los padres observan, a veces, el crecimiento de sus hijos como espectadores de algo natural e inevitable, de algo que no pueden predecir ni controlar. Y esta incertidumbre de un proyecto, que no es el "Suyon, les puede ayudar a no intentar hacer una réplica o calco de sus vidas en la vida de sus hijos. La acogida del otro, también la del hijo, no es reproducirse en el hijo, sino hacer lo posible para que el otro sea él mismo, reconocerlo en su alteridad irrenunciable.

La acogida en la familia significa para el niño sentirse protegido por el amor y el cuidado de sus padres. Significa apoyo, ternura, confianza; sentir cercana la presencia de los padres que se hace dirección, guía, acompañamiento. Significa seguridad, sentirse invulnerable.

Es en el nido familiar, cuando este funciona con la debida eficacia, donde uno paladea por primera y quizá última vez la sensación reconfortante de esta invulnerabilidad. Por eso los niños felices nunca se restablecen totalmente de su infancia y aspiran durante el resto de su vida a recobrar como sea su fugaz divinidad originaria. Aunque no lo logren ya jamás de modo perfecto, ese impulso inicial les infunde una confianza en el vínculo humano que ninguna desgracia futura puede completamente borrar (Savater, 1997, 57).

Educar es básicamente acoger, facilitar un espacio y un clima de afecto, cuidado y seguridad que permita vivir la aventura de la construcción de la propia vida. Es bacerse presente, desde experiencias valiosas, en la vida de los hijos como 
alguien en quien se puede confiar. En la acogida el niño empieza a tener la experiencia de la comprensión, del afecto y del amor, del respeto hacia la totalidad de lo que es, experiencia que puede ver plasmada en los demás miembros de la familia porque ellos también son acogidos. En adelante, el aprendizaje de la tolerancia y el respeto a la persona del otro lo asociarán con la experiencia de ser ellos mismos acogidos, y no sólo en lo que la tolerancia tiene de respeto a las ideas y creencias de los demás, sino de aceptación de la persona concreta del otro. La acogida es reconocimiento de la radical alteridad del otro, de su dignidad; es salir de uno mismo para reconocerse en el otro; es donación y entrega. Es negarse a repetirse, clonarse en el otro, para que el otro tenga su propia identidad. "Entre el padre y el hijo, como entre el educador y el educando o el maestro y el discípulo, constituyen formas de relación que se fundan en la discontinuidad del quién" (Bárcena, 2002, 513). Y, a su vez, es también responsabilidad, compromiso, hacerse cargo del otro. Desde la cercanía a los hijos, desde la presencia en la vida de los hijos, la convivencia con ellos, la acogida, se experimenta más como "un estilo de vida" que como un modo de "hacer cosas" con ellos. Se ve más como una experiencia en la que todos se ven implicados que como una tarea que va en una única dirección.

En esta experiencia primigenia el hijo empieza su largo aprendizaje de la acogida. No es congruente esperar que los niños sean tolerantes y acogedores para con los otros, si previamente no han tenido la experiencia de ser acogidos, y no han aprendido a acoger en la vida cotidiana del ámbito familiar. Y acoger al otro no por sus ideas y creencias, sino por lo que es. Más allá de cualquier razón argumentativa, el otro se nos impone por la dignidad de su persona. No son las ideas y las creencias en sí mismas las que constituyen el objeto de la acogida, sino la persona concreta que vive aqui y abora, y exige ser reconocida como tal. Entender esto así supone hacer recaer en la aceptación y acogida del otro toda la acción educativa. La experiencia de la acogida en el seno de la familia, en una sociedad tan fuertemente "desvinculada" como la nuestra, puede constituir un muro sólido contra la intolerancia y el racismo. Sólo la acogida del otro, desde el reconocimiento de su irrenunciable alteridad, nos puede librar de toda tentación totalitaria. Pero acoger, aceptar y respetar al otro también se aprende. Es fruto de una larga experiencia de acogida, y en esto la familia es indispensable.

La acogida se hace a la persona total del otro, con su realidad presente y sus proyectos. Pero la acogida, a la vez que es donación y entrega, es también responsabilidad.

El recién nacido, escribe Manen (1998, 153), descentra el mundo de la mujer y del hombre a un mundo de madre o padre y, por consiguiente, la mujer se convierte en madre y el hombre en padre. Algunos tienen más dificultad que otros para aceptar la responsabilidad de hacer sitio en sus vidas para los niños. Pero más pronto o más tarde el nuevo padre o madre experimentan el nacimiento del niño como una llamada. El recién nacido, desde su vulnerabilidad, pide que le cuiden. Y la experiencia de esta llamada me convierte de mujer en madre y de hombre en padre. Ahora debo actuar en armonía solícita hacia el otro, para el otro. 
La relación padre/madre-hijo comienza con una respuesta a la demanda del otro. Su presencia es llamada, apelación, exigencia de cuidados para que el otro "llegue a ser" otro, no la réplica de nadie. Esta nueva relación provoca una actividad, un aprendizaje que implica a todos los miembros de la familia en una experiencia singular. Por una parte, el padre y la madre aprenden a actuar como tales y, por otra, el hijo actúa como aprendiz de lo humano. Se trata, por tanto, de un acontecimiento educativo que va más allá de lo que habitualmente se ha considerado como enseñanza y aprendizaje. La familia se ocupa de "otro modo de enseñar y de aprender". En cuanto estructura de acogida, la familia es lugar "natural" donde se concretan los modos cotidianos de vida, es decir, donde surgen formas muy variadas de transmisión y en el que se aprende conjuntamente (padres e hijos) a desvelar los problemas y a buscar posibles modos de resolverlos. En una sociedad tan "anónima" como la nuestra, en la que los vínculos de integración a marcos estables de convivencia se han debilitado, la familia es, quizás, el último reducto o espacio que queda al hombre de hoy para ser reconocido y acogido como tal.

Y entonces, ¿qué enseñar en la familia? No es fácil responder a esta pregunta porque no estamos ante un solo modelo de familia: hay muchas familias con distintas concepciones sobre lo que significa la realización humana, en qué y cómo; por tanto, muchas formas de entender y "hacer" la educación de los hijos. Por otra parte, no nos sentimos cómodos con el término "enseñar" cuando nos referimos al ámbito de la familia; ni consideramos pertinente hacer un elenco de valores que deberían ser enseñados en la familia. Sí vemos necesario identificar "condiciones ambientales" imprescindibles para la educación de los hijos, cualquiera que sea el sistema de valores en el que la familia se apoye. Junto a la acogida, es necesario crear en la familia un clima moral (de responsabilidad) y de diálogo en el que los valores de tolerancia, justicia, solidaridad, etc., vayan tomando cuerpo. Los valores morales no se enseñan ni se aprenden porque se "hable" de ellos, sino porque se practican, porque se hacen experiencia.

Creemos que el término "enseñar" cuando se habla de educación familiar no es el más adecuado, tiene evidentes connotaciones académicas. Se enseñan matemáticas, lengua, historia y geografía. Y entonces se transmiten saberes o conocimientos. Pero cuando hablamos de educar nos referimos a "otra cosa". Y esta distinción no es una cuestión sólo de términos, afecta, por el contrario, al núcleo mismo del discurso sobre educación familiar. Educar no es sólo enseñar, y enseñar bien. En el núcleo del acto educativo hay siempre un componente ético, una relación ética que liga a educador y educando y que se traduce en una actitud de acogida y de compromiso, en una conducta moral de bacerse cargo del otro. Es esta relación ética, responsable la que define y constituye como tal a la acción educativa. Sin este componente ético estaríamos hablando de otra cosa, no precisamente de educación. En la relación educativa el primer movimiento que se da es el de la acogida, de la aceptación de la persona del otro en su realidad concreta, no del individuo en abstracto; es el reconocimiento del otro como alguien, valorado en su dignidad de persona y no sólo el aprendiz de conocimientos y competencias. 
Educar exige, en primer lugar, salir de si mismo para acoger, "es hacerlo desde el otro lado, cruzando la frontera" (Bárcena y Mèlich, 2003, 210); es ver el mundo desde la experiencia del otro, hacer que el otro tenga la primacía y no sea sólo el otro lado o parte de una acción puramente informativa. Y en segundo lugar, exige la respuesta responsable a la presencia del otro. En una palabra, bacerse cargo del otro, asumir la responsabilidad de ayudar al nacimiento de una "nueva realidad", a través de la cual el mundo se renueva sin cesar (Arendt, 1996). Si la acogida y el reconocimiento son indispensables para que el recién nacido vaya adquiriendo una fisonomía auténticamente humana (Duch, 2002), la acogida y el hacerse cargo del otro es una condición indispensable para que podamos hablar de educación. Parece, por tanto, que cuando hablamos de educación hacemos referencia a un acto de amor de alguien que ayuda a la existencia de una nueva criatura (Arendt, 1996), original en su modo de existir, no a la clonación o repetición de modelos preestablecidos que han de ser miméticamente reproducidos; hablamos de alguien que asume la responsabilidad de hacerse cargo del otro, que no se busca a sí mismo ni pretende prolongarse en el otro. Educar, entonces, ya no es sólo transmitir, enseñar el patrimonio de cultura a las jóvenes generaciones, sino ayudar al nacimiento de algo nuevo, singular, a la vez que continuación de una tradición que ha de ser necesariamente reinterpretada; "es una pasión con sus propios dolores y placeres" (Manen, 1998, 87). Y en esta función de acogida y reconocimiento del otro, de hacerse cargo del otro, de dirección y protección la familia ocupa un puesto privilegiado e insustituible. Este aspecto de cuidado y protección, inherente al concepto de educación, no ha sido suficientemente atendido y entendido, hasta ahora. Manen $(1998,54)$ se hace eco de ello: “... hay que conferir a la noción de pedagogía un significado que todavía merece que le prestemos atención. La idea original griega de la pedagogía lleva asociado el significado de dirigir en el sentido de acompañar, de tal forma que proporcione dirección y cuidado a la vida del niño".

\subsection{Clima moral}

No es nuestra intención introducir un discurso moralizante de la vida familiar con un listado exhaustivo, y siempre incompleto, de los deberes de los padres en la educación de los hijos; no pretendemos regular inútilmente toda la vida familiar. Regular, controlar, en alguna medida, la vida de los hijos puede significar ejercer un determinado tipo de protección y cuidado sobre ellos, una manera de hacernos presentes en su vida. Pero orientar las relaciones padres-hijos, fundamentadas en el espíritu de la disciplina y el orden, o en el cumplimiento rígido de las normas puede significar la prolongación de la minoría de edad de los hijos e impedir que vayan asumiendo progresivamente mayores niveles de responsabilidad. Aquí hablamos de "otra moral", la que nos hace responsables de los otros y de los asuntos que nos conciernen como miembros de una comunidad, empezando por la propia familia. Lamentablemente, no es éste un discurso frecuente en la educación 
familiar, tampoco en el ámbito de la ética y de la política. "Pese a la importancia que tiene en la formación ética y social de la persona aprender a responder de lo que uno hace o deja de hacer, la llamada a la responsabilidad ha estado ausente del discurso ético y político de los últimos tiempos. La ética hace tiempo que está más centrada en los derechos que en los deberes" (Camps y Giner, 1998, 138). Interiorizar la relación de dependencia o responsabilidad para con los otros, aun con los desconocidos, significa descubrir que vivir no es un asunto privado, sino que tiene unas repercusiones inevitables mientras sigamos viviendo en sociedad, pues no hemos elegido vivir con los que piensan igual que nosotros o viven como nosotros. Por el contrario, hemos venido a una sociedad muy heterogénea con múltiples opciones en las formas de pensar y vivir. Ello implica tener que aprender a convivir con otras personas de diferentes ideologías, creencias y estilos de vida. Vivir con los otros genera una responsabilidad. O lo que es lo mismo, nadie me puede ser indiferente, y menos el que está junto a mí. Mi conducta no empieza y acaba en mí en cuanto a sus consecuencias. Junto a mí hay otros a quienes mi conducta u omisión pueden afectar y me pueden pedir explicaciones. Frente al otro he adquirido una responsabilidad de la que no me puedo desprender, de la que debo dar cuenta. El otro, cualquier otro siempre está presente como parte afectada por mi conducta en la que el otro se pueda ver afectado, sin más argumento que su dignidad de persona. No puedo abdicar de mi responsabilidad hacia él.

El rostro del otro me concierne sin que la responsabilidad-respecto-de-otro que ordena me permita remontarme hasta la presencia temática de un ente que sería la causa o la fuente de tal orden. No se trata aquí, en efecto, de recibir una orden percibiéndola primero y obedeciéndola después mediante una decisión o un acto de voluntad. La sujeción a la obediencia precede, en esa proximidad del rostro, a la comprensión de la orden (Levinas, 2001, 181).

Esto significa que el ser humano es alguien que desde el nacimiento hasta su muerte, lo quiera o no, está constreñido a "actuar" en relación con los otros (Duch y Mèlich, 2004).

Pero la responsabilidad de la que aquí hablamos no se limita a "dar cuentan de aquello que hacemos u omitimos porque alguien nos lo demanda en una relación estrictamente ética. Comprende, además, el ámbito del cuidado, de la atención y solicitud hacia la vulnerabilidad del otro. Manen $(1998,151)$ lo expresa de este modo:

El hecho fascinante es que la posibilidad que tengo de experimentar la alteridad (responsabilidad) del otro reside en mi experiencia de su vulnerabilidad. Es justo cuando yo veo que el otro es una persona que puede ser herida, dañada, que puede sufrir, angustiarse, ser débil, lamentarse o desesperarse, cuando puedo abrirme al ser esencial del otro. La vulnerabilidad del otro es el punto débil en el blindaje del mundo centralizado en mí mismo.

Esta moral de la atención y cuidado (care) hacia el otro se traduce en el desarrollo de la empatía como "capacidad del hombre de imaginar el dolor y la degradación 
causados a otro como si lo fueran a sí (mismo)" (Hoffman, 2002, 249), y facilita: a) ponerse en el lugar del otro, comprenderlo y reconocerlo; b) el desarrollo de la conciencia de pertenencia a una comunidad frente a la cual se tienen unas obligaciones que no se pueden eludir sin producir un daño a los demás; c) el desarrollo de la capacidad de escucha, acogida y atención al otro como condición primera de una relación moral o responsable con los demás; d) la capacidad de analizar críticamente la realidad del entorno desde parámetros que respondan a la dignidad de la persona. Ser responsable es poder responder del otro, cuidar y atender al otro. Y esto también se aprende en la familia. No es, por tanto, una educación moralizante que empieza y acaba en un elenco interminable de consejos, bastante ineficaces, para orientar la vida de los hijos. Más bien es una propuesta y "exposición" de modelos de cómo responder a las demandas de los demás. Si algo identifica al ser humano es su capacidad de responder de sus actos. Potenciar la responsabilidad en los educandos es profundizar en su humanización. Es, en una palabra, educar.

\subsection{Clima de diálogo}

La comunicación se ha entendido, no pocas veces, como un intento de persuadir y convencer al otro de "mi verdad", como un acto de imposición y dominio. La comunicación humana, y más propiamente el diálogo, supone y exige la voluntad en los interlocutores de aceptar la parte de verdad del otro y el reconocimiento de la provisionalidad o precariedad de la propia verdad (Ortega y Mínguez, 2001). La comunicación humana no se nutre ni agota en contenidos exclusiva ni principalmente "intelectuales", mucho menos en el ámbito familiar. Más allá de las ideas, creencias y opiniones en la comunicación humana se comunica el sujeto concreto en todo lo que es y a través de todo lo que es. Y no sólo nos comunicamos a través de la palabra o la escritura. También lo hacemos con los gestos, el silencio, las emociones, la expresión del rostro, etc. El ser humano encuentra modos inimaginables para expresar lo que piensa y siente. Aprender a comunicarse, a ver el punto de vista del otro, a comprender y aceptar que el otro también tiene derecho a "decir su palabran; reconocer que no existe ser humano al que se le pueda negar la palabra, y que ejercer de humanos supone el ejercicio de la palabra creadora de vida, exige revisar un conjunto de prácticas encaminadas a imponer la "autoridad" de los mayores.

El diálogo no es "decir cosas", es encontrarse con el otro a quien se hace entrega de "mi verdad" como experiencia de vida. Y más que discurso, el diálogo es confianza, acogida y escucha. Nadie se comunica con otro en el diálogo, o deposita en él "Su" experiencia personal de vida, si el otro no es merecedor de su confianza. El diálogo es, además, donación y entrega gratuita. En el diálogo no se da nunca una relación de poder que genere sumisión en uno de los interlocutores; se establece más bien una relación ética que hace del reconocimiento del otro una cuestión irrenunciable. El lenguaje del diálogo «es el lenguaje del recibimiento del otro en la casa... que es propia. El que viene de fuera (el extranjero, el otro) puede 
o no ser recibido allí donde va. Pero si es recibido, este recibimiento es un recibimiento hospitalario" (Bárcena y Mèlich, 2000, 159). Quizás sea ésta la necesidad más sentida en nuestra sociedad y especialmente en nuestros adolescentes y jóvenes. Nuestra sociedad de la hipercomunicación, paradójicamente, se ha convertido en la sociedad de la incomunicación. Padecemos una crisis de "transmisiones". No hemos encontrado todavía los modos adecuados que nos permitan transmitir a las jóvenes generaciones las claves de interpretación de los acontecimientos que han configurado nuestra historia personal y colectiva. Esta fractura generacional y social produce desconcierto y orfandad. "Lo que ahora mismo se necesita con urgencia, escribe Duch (1997, 63), es una adecuada praxis transmisora que nos proporcione las palabras y expresiones convenientes para que el diálogo pueda convertirse en una realidad palpable, y no en una mera declaración verbal de "buenas intenciones". En la sociedad premoderna, las transmisiones hechas desde y en las estructuras de acogida resultaban más eficaces y menos problemáticas. En la modernidad, sin embargo, la contingencia y la provisionalidad se convierten en una categoría fundamental para explicar la nueva situación del hombre en el mundo. Éste ha de "habérselas" en un medio de innumerables dudas, fugacidades e inconsistencias (Duch, 2001). Por otra parte, la sobreaceleración del tiempo es un elemento añadido que ha influido decisivamente en la sociedad actual. Puede afirmarse que la actual preeminencia del presente en la experiencia de la secuencia temporal de los individuos y de las colectividades va unida a la aceleración creciente e imparable del curso del tiempo, del tempo vital. Este hecho tiene unas enormes repercusiones en la experiencia ética, en la adopción de unos determinados valores, en la configuración de la conciencia moral de las personas y en las respuestas de los individuos y de los grupos humanos en la vida de cada día. La velocidad con la que actualmente aparecen y desaparecen las innovaciones no tiene paralelismo en la historia pasada de las culturas. Esta sobreaceleración del tiempo debería obligar a los individuos a tomar una posición moral con la misma velocidad con la que irrumpen las innovaciones en nuestra sociedad. Pero curiosamente acostumbra a producir, de un lado, un "hipermercado de valores" provisionales, frágiles y en competición; de otro, sujetos humanos con una identidad exclusivamente instantánea, es decir, sin referencias a la anticipación y al recuerdo, a la tradición y a la utopía. Se trata, por tanto, de sujetos humanos descolocados respecto de su propia trayectoria vital, bloqueados y enajenados respecto de sí y de los demás (Duch, 2002). En esta situación de "emergencia" la familia podría convertirse en el último reducto de "seguridad y confianza", de anclaje en el presente y espacio de interpretación del pasado, donde el individuo puede comunicarse, expresarse y vivir experiencias, aunque sean contradictorias, de valores y antivalores.

En la sociedad postmoderna no sólo es difícil encontrar espacios y momentos para el diálogo en la familia sino, además, de qué dialogar, cuando las experiencias de vida de los hijos, instantáneas y fugaces, distan mucho en el tiempo de las vividas por los padres. Si el diálogo es comunicación, y no sólo discurso, de la experiencia vital de los interlocutores, éste debe necesariamente estar centrado en las 
experiencias vividas por todos los miembros de la familia. Si decimos que las narraciones constituyen recursos poderosos para la educación en valores, entonces la vida de los padres, hecha narración, constituye el mejor instrumento para la educación de los hijos. Conocer al padre y a la madre en sus dudas, fracasos y aciertos, en su trayectoria vital, cómo han superado las dificultades y cómo las afrontan ahora es un contenido ineludible del diálogo entre padres e hijos. "Nuestras "historias" constituyen el resumen vital y narrativo de las sucesivas asociaciones de espacio y tiempo que hilvanan el tejido de toda existencia humana" (Duch, 2001, 3). Es verdad que se corre el riesgo de enfrentarnos a experiencias positivas y negativas. Pero se habrá ganado en realismo, acercando el "personaje" de los padres a la vida real de los hijos. Sólo si el modelo aparece como humano, cercano a nosotros, aquél es imitable. La propuesta artificial, descontextualizada de los valores, por el contrario, difícilmente supera el ámbito del concepto, y es del todo insuficiente para mover al sujeto a su apropiación (Ortega y Mínguez, 2001). El diálogo debe estar centrado, además, en la vida actual de los hijos: en sus dudas, frustraciones, éxitos, aspiraciones; en las experiencias de sus vidas. Y entonces el diálogo con los hijos se hace acompañamiento, dirección, protección y cuidado, que se traduce en una actitud de escucha, no en un discurso retórico y disciplinar, que además de estéril puede resultar contraproducente.

El diálogo no se debe desnaturalizar hasta el punto de convertirlo en una herramienta ni pretexto para hablar de los hijos. Por el contrario, es un momento de encuentro entre todos que adopta formas diversas y en tiempos distintos. Nada más contraproducente que "formalizar" o institucionalizar el diálogo. A veces el diálogo se convierte en sola presencia, compañía, cercanía. Puede ser suficiente para los hijos saber (experimentar) la presencia física de los padres, que están ahí, cerca. Y que un gesto, una caricia, una sola palabra basta para comunicar y expresar todo el apoyo y la comprensión que se espera, pero también la desaprobación de aquello que se considera incorrecto. El diálogo es también una actitud de disponibilidad. Estar dispuesto a escuchar, a acoger sin contraprestaciones, a uperder el tiempo" en la confianza de encontrar en el otro la ayuda y la comprensión en la búsqueda de "mi" camino. El itinerario obligado en el aprendizaje de los valores, hemos dicho, es la identificación con un modelo, es la experiencia del valor. La familia educa a través de todo aquello que día a día, en un clima de afecto, va baciendo aun en medio de continuas contradicciones. Para los hijos, éstas no son obstáculos insalvables en la apropiación o aprendizaje del valor porque tienen a su alcance la posibilidad de contrastar una experiencia negativa (antivalor) con la trayectoria de vida de sus padres en la que se ensamblan valores y antivalores.

$\mathrm{Y}$ ¿qué enseñar? Decíamos antes que los padres deben crear las condiciones "ambientales" para la apropiación o aprendizaje de los valores. Nos resistíamos, por tanto, a hacer una propuesta concreta de aprendizaje de valores. Cabe, eso sí, la oferta, desde la experiencia, de aquellos valores que se consideran básicos para la formación de la persona moral y la construcción de una sociedad justa y solidaria. Se trata, al menos, de aquellos valores personal y socialmente indispensables, compartidos 
y exigibles en una sociedad democrática. Deberíamos incidir en la necesidad de crear un ambiente familiar que haga posible la acogida y el reconocimiento y paliar, en lo posible, la fractura de la confianza que caracteriza a la sociedad actual. Donde no hay confianza los procesos de transmisión se tornan irrelevantes, superfluos, generan actitudes de indiferencia y crean desorientación. Por el contrario, un clima de confianza reduce la complejidad que se origina en la convivencia humana y favorece la búsqueda de "sentido", o lo que es lo mismo, la confianza ejerce las funciones de praxis de dominación de la contingencia y la provisionalidad (Duch, 2001). Además de crear las condiciones "ambientales" que permitan crecer y ejercer de humanos a los hijos, a éstos se les debería enseñar a

reflexionar sobre nosotros mismos, sobre las cosas, sobre nuestra condición en el mundo, sobre el ser de los demás... (a) tomar distancias respecto a lo que nos rodea y lo que constituye nuestro propio ser, mirarse uno mismo como si se fuese otro... (a preguntarnos) quiénes somos, por qué hay algo y no la nada... (Crespi, 1996, 54-55).

Es decir, ayudarles a aprender a existir, aunque este aprendizaje nunca puede considerarse concluido. Si el ser humano, por imperativo cognitivo, desea entender el mundo, la familia constituye la puerta de acceso al conocimiento de un mundo humano a través de procesos de delimitación y definición del yo, de los otros, de la naturaleza, del tiempo y del espacio. Cómo son las cosas y las personas, cómo sentir, buscar y admirar, qué debo hacer, dónde estoy son aprendizajes que tienen su raíz profunda en el ámbito de la familia. "Es un conocimiento que surge tanto de la cabeza como del corazón" (Manen, 2003, 16). Estas preguntas y la ayuda a responderlas constituyen el contenido de la enseñanza de los padres a los hijos.

Al comienzo de este trabajo nos hacíamos una pregunta: ¿Crisis en la familia? La respuesta no puede darse al margen de la observación atenta de la nueva realidad social. Los modelos de familia siempre van a estar sometidos a cambios, ligados a las sucesivas transformaciones sociales y culturales. La familia no es un receptor pasivo de los cambios sociales, ni un elemento inmutable de un mundo en constante transformación (Gracia y Musitu, 2000), por lo que siempre se podrá hablar, con mayor o menor fortuna, de "crisis" en la familia. Se sucederán los modelos, pero "para el cultivo inteligente y afectivo de la personalidad infantil, para la espontaneidad en el trato interpersonal, la expresión de sentimientos, la intimidad y el altruismo, el más adecuado ambiente seguirá siendo la familia" (Pastor, 2002, 192). No consideramos a la familia como una institución construida, ni exclusiva ni principalmente, sobre la biología, el derecho, la política o las costumbres más o menos consolidadas, sino sobre el ejercicio de la responsabilidad, de la aceptación de responsabilidades inherentes a cualquier tipo de respuesta ética, como espacio de acogida y reconocimiento del ser humano. El llamado "contrato" familiar debería ser siempre un "contrato ético", "convivencial", que debería poner de relieve el cúmulo de relaciones, reciprocidades y tensiones que acompañan a la presencia 
del ser humano en su mundo cotidiano. La experiencia personal y colectiva nos dice que toda vida humana es más o menos inventada y vivida sin un guión previo. Pero en esta "aventura" de la vida nadie está sólo. Desde nuestro nacimiento somos acogidos en una tradición simbólico-cultural familiar que nos aporta todo un conjunto de pautas de comportamiento y puntos de apoyo, de referentes que nos permiten hacer frente a la contingencia, es decir, al conjunto de interrogantes que no pueden responderse técnicamente, que permanecen incontestables y opacos para los "expertos" de todos los tiempos (Duch y Mèlich, 2004). La familia hace posible, como dice Arendt (1996), el milagro del nacimiento de una nueva criatura por la que el mundo deja de ser "el mismo" para renovarse sin cesar.

\section{BiBLIOGRAFÍA}

ARENDT, H. (1996) Entre el pasado y el futuro. Barcelona, Península.

- (1999) Los orígenes del totalitarismo. Madrid, Taurus.

BÁRCENA, F. y MÉLICH, J. C. (2000) La educación como acontecimiento ético. Barcelona, Paidós.

- (2003) La mirada excéntrica. Una educación desde la mirada de la víctima, Revista Española de Pedagogía, 223, 501-520.

BARUDY, J. (1998) El dolor invisible de la infancia. Una lectura del maltrato infantil. Barcelona, Paidós.

BerCK-Gernsheim, E. (2003) La reinvención de la familia. Barcelona, Paidós.

Beltrán, J. (2001) Educación familiar e intervención técnica, en AA.VV. Familia, juventud y nuestros mayores: la actitud proactiva. La Coruña, Fundación Caixagalicia, 15-54.

BELTRÁN, J. y PÉREZ, L. F. (2000) Educar para el siglo XXI. Madrid, CCS.

BERKowITZ, L. (1996) Agresión. Causas, consecuencias y control. Bilbao, DDB.

BeShAROv, D. (ed.) (2003) Family Well-being After Welfare Reform. New York, Transaction Publ.

CAMPs, V. y Giner, S. (1998) Manual de civismo. Barcelona, Ariel.

CASTELL, M. (1998) La era de la información, vol. II. Madrid, Alianza.

CASTRO, J. A.; Adonis, D. y Rodríguez, M. (2001) ¿Es la actitud violenta de los adolescentes un producto de la educación familiar? Un análisis causal en función del género, Revista de Ciencias y de Orientación Familiar. Familia, 23, 25-44.

CEREZO, F. (1999) La relación agresión-victimización: variables de personalidad asociadas en sujetos de 10 a 15 años. Actas del II Congreso de la Asociación Española de Psicología Clínica y Psicopatología. Murcia.

- (2001) La violencia en las aulas. Madrid, Pirámide.

CRESPI, F. (1996) Aprender a existir. Nuevos fundamentos de la solidaridad social. Madrid, Alianza.

DAHRENDORF, R. (1993) La democracia en Europa. Madrid, Alianza.

Dalton, R. J. y otros (1992) El reto de los nuevos movimientos sociales, en DalToN, R. J. y KueCHLER, M. (comps.). Los nuevos movimientos sociales. Valencia, Alfons el Magnànim Ed.

Duch, Ll. (1997) La educación y la crisis de la modernidad. Barcelona, Paidós.

- (2001) La educación y la crisis de la modernidad. Ponencia presentada en el Seminario: La educación ante el cambio social. Murcia, Obra Cultural de Cajamurcia, 2 al 5 de abril.

(C) Ediciones Universidad de Salamanca

Teor. educ. 15, 2003, pp. 33-56 
- (2002) Antropologia de la vida cotidiana. Madrid, Trotta.

- (2002) La substància de l'efimer. Assaigs d'antropología. Barcelona, Publications de l'Abadía de Montserrat.

Duch, Ll. y MÈLICH, J. C. (2004) Ambigüitats de l'amor. Barcelona, Publications de l'Abadía de Montserrat (en prensa).

EisenberG, N.; FABes, R. A. y MurPhy, B. C. (1996) Parent's reactions to children's negative emotions: Relations to children's social competence and conforting behavior, Child Development, 61 (1), 113-126.

EUROSTAT (2000) The Social Situation in European Union. Luxemburgo, Office for Official Publications of the European Communities.

FERNÁNDEZ ENGUITA, M. (2001) Educar en tiempos inciertos. Madrid, Morata.

FLAQUER, Ll. (1998) El destino de la familia. Barcelona, Ariel.

FuKuyama, F. (1999) The great disruption: Human nature and the reconstitution of social order. New York, The Free Press.

Gimeno, A. (1999) La familia: el desafio de la diversidad. Barcelona, Ariel.

Gracia, E. y Musitu, G. (2000) Psicología social de la familia. Barcelona, Paidós.

Hoffman, M. L. (2002) Desarrollo moral y empatía. Barcelona, Idea Books.

Iglesias De UsSEL, J. (1998) La familia y el cambio político en España. Madrid, Tecnos.

KoCHANSKA, G. (1997) Mutually responsive orientation betwen mathers and their young children. Cbild Development, 68 (1), 94-112.

Krevans, J. y GibBs, J. C. (1996) Parent's use of inductive discipline: Relations to children's empaty and prosocial behavior, Child Development, 67 (6), 3267-3277.

LeVinas, E. (2001) Entre nosotros. Valencia, Pre-textos.

MaldincKrodT, B. (1992) Childhood emotional bonds with parents, development of adult social competencies, and availability of social support, Journal of Counseling Psycho$\log y, 39,453-561$.

MANEN, V. F. (1998) El tacto en la enseñanza: el significado de la sensibilidad pedagógica. Barcelona, Paidós.

- (2003) El tono en la enseñanza. Barcelona, Paidós.

ORIzo, F. A. y otros (2000) España 2000 entre el localismo y la globalidad. Encuesta Europea de Valores en su tercera aplicación 1981-1999. Madrid, S. M.

OrTEGA, P. y Mínguez, R. (2001) Los valores en la educación. Barcelona, Ariel.

Ortega, P.; Mínguez, R. y Saura, P. (2003) Conflicto en las aulas. Barcelona, Ariel.

Ortega, R. (1997) El proyecto Sevilla Anti Violencia Escolar (SAVE). Un modelo de intervención preventiva contra los malos tratos entre iguales, Revista de Educación, 313.

PASTOR, G. (2002) La familia en España. Sociologia de un cambio. Salamanca, Sígueme.

Pérez-Díaz, V.; Chulia, E. y Valiente, C. (2000) La familia española en el año 2000. Madrid, Argentaria-Visor.

Popenoe, D. (1993) American Family Decline, 1960-1990: A review and appraisal, Journal of Marriage and the Family, 55, 3, 527-555.

Rodríguez Neira, T. (2003) Pedagogía y educación familiar, en Gervilla, E. (coord.). Educación familiar. Nuevas relaciones bumanas y bumanizadoras. Madrid, Narcea.

SAVATER, F. (1997) El valor de educar. Barcelona, Ariel.

Tedesco, J. C. (1995) El nuevo pacto educativo. Madrid, Anaya.

Thiebaut, M. (1998) Perspectivas para una cultura familiar del siglo xxI, en BoroBIo, D. (coord.). Familia y cultura. Salamanca, Servicio de Publicaciones de la Universidad Pontificia de Salamanca. 